\title{
The Determinants of Anthropometric Deficits in Children under Five Years Old in Tete Province Mozambique Using Hierarchy Approach
}

\author{
Jonas B. Daniel ${ }^{1}$, Elisabete Pinto² ${ }^{2}$ Valterlinda de Oliveira Queiroz ${ }^{1}$, Ana Marlucia de Oliveira1 \\ ${ }^{1}$ School of Nutrition, Federal University of Bahia, Salvador, Brazil \\ ${ }^{2}$ Center of Health Sciences, Federal University of Recôncavo of Bahia, Santo António de Jesus, Brazil \\ Email: *Jonasbaltazar.danielb@gmail.com
}

How to cite this paper: Daniel, J.B., Pinto, E., Queiroz, V. de O. and de Oliveira, A.M. (2019) The Determinants of Anthropometric Deficits in Children under Five Years Old in Tete Province Mozambique Using Hierarchy Approach. Open Journal of Epidemiology, 9, 15-26.

https://doi.org/10.4236/ojepi.2019.91002

Received: October 23, 2018

Accepted: December 26, 2018

Published: December 29, 2018

Copyright ( 2019 by authors and Scientific Research Publishing Inc. This work is licensed under the Creative Commons Attribution International License (CC BY 4.0).

http://creativecommons.org/licenses/by/4.0/

\section{c) (i) Open Access}

\begin{abstract}
Introduction: The malnutrition in children under 5 years is a serious public health problem in the developing countries such as Mozambique. The stunting can affect cognitive and physical development and compromise the school performance. Method: A cross sectional study was carried out which used the secondary data from a survey conducted by National Health Institute of Mozambique, in districts of Angonia, Tsangano, Magoe and Changara in Tete Province, Mozambique. The polynomial regression model and the hierarchical approach were used to examine the association between social economic factors and malnutrition in children measured by stunting (low height for age) and underweight (low weight for age). Results: The prevalence of moderate and severe stunting was $39.8 \%$, and prevalence of moderate and severe underweight was $19.6 \%$. In the basic level, the households that had 1 durable goods possession were associated to 1.46 times greater than the mild underweight, $\mathrm{OR}=1.46$ (C.I. 95\% $1.02-2.11$ ). In the intermediate level, lack of latrine increased 2.01 times greater than the moderate and severe underweight in children, OR $=2.01$ (C.I. 95\% 1.09 - 3.70); In the immediate level, the child deworming had 1.91 times greater than the moderate and severe stunting, $\mathrm{OR}=1.91$ (C.I.95\% 1.04 - 3.52) and children who did not breastfeed had 2.42 times greater than the moderate and severe stunting, OR $=2.42$ (C.I. 1.49 - 3.43). Conclusion: In the countries where the weak health system and the inadequate children food are frequent, the prevalence of undernutrition in children remains very high.
\end{abstract}

\section{Keywords}

Child, Underweight, Stunting, Hierarchy Approach, Tete, Mozambique 


\section{Introduction}

Malnutrition is a public health problem in developing countries. It affects more than one third of children and is directly associated with morbidity and mortality in children under 05 years old in the world [1]. The underweight (low weight for age) and stunting (low height for age) are declining worldwide from 1990 to 2010 , while the prevalence of underweight and stunting decreased from $24.8 \%$ to $16.2 \%$ and $39.9 \%$ to $24.8 \%$ respectively [2]. In the African continent, especially in north of Africa the prevalence of underweight in children under five years decreased from $30 \%$ to $18.4 \%$ [2]. In Sub-Saharan Africa it decreased from $48.2 \%$ to $38.7 \%$ [2]. For Mozambique, in 2011 the prevalence of underweight in children under five was $15.0 \%$ and the stunting was estimated to be $42.3 \%$ [3]. Research carried out in 2011, Tete Province with representative sample of children under five years, showed the prevalence of stunting was $42 \%$ (Mozambique, Demographic and Health inquiry, 2011) [3]. Factors such as biologics and pathologics are also recognized as etiological factors of undernutrition [4]. Results of studies conducted in many regions of the world, such as India in 2014, showed that malnutrition in children under 5 years is associated with food insecurity, inappropriate feeding practices and diseases [5]. These determinants are also observed in Mozambique among the most socially and economically vulnerable groups [6]. Currently, Mozambique has systematic information on anthropometric status in childhood [7]. Result of study conducted in 2014 by Cruz et al., in rural area of Tete Province showed that the prevalence of stunting was $36.2 \%$ in children under five years old [8]. In Mozambique, studies of the association between socioeconomic determinants and anthropometric status in children are scarce. The objective of this study was to estimate the prevalence of undernutrition in children under five years old and examine the socioeconomic factors, according to the basic intermediate and immediate levels of hierarchy in the districts of Angonia, Tsangano, Magoe and Changara in the Province of Tete, Mozambique.

\section{Methodology}

\subsection{Study Design}

This was a cross-sectional study based on secondary data from the research on malnourished children carried out by National Institute of Health in 2012 (IAFNUT-2012) in the districts of Angonia, Tsangano, Magoe and Changara, in the province of Tete-Mozambique.

\subsection{Sampling}

The sample of this study is representative survey on malnourished children carried out in selected districts of Tete Province. To select the participants, 12 communities from each district was selected; and then 48 communities in four districts, 1248 households were selected in four districts. The households with at least one child 0 - 59 months was randomly selected, only 583 children were in- 
cluded in this study.

The sample size was calculated based on the prevalence of stunting estimated in $43 \%$ in Mozambique. It was previously established by UNICEF [9]. To calculate this sample size was taken in account the effect of study design in $4 \%$. According to the World Health Organization (WHO), all records from the anthropometric status contain $\mathrm{Z}$ scores values $<-5$ and $>+5$ to weight for age and $<-5$ and $>+3$ to height for age should be excluded for statistical analysis [10].

\subsection{Ethical Approval}

The study proposal was submitted to the ethics committee for the human health studies from the National Institute of Health Mozambique and it was approved. Before the start of the study, all participants who agreed to participate in the study, signed the free consent and informed form.

\subsection{Data Collection}

Data were collected between 1 September and 30 October by four trained teams. The information was provided by the mother or the child's caregiver and recorded in two questionnaires, one for the household and another for the mothers and children.

Children were weighed in SECA brand scales with capacity of $25 \mathrm{~kg}$ and \pm 100 g precision calibrated after every 2 weighings. Height was measured by a stadiometer (SECA) and the length of those of up to 2 years was measured with infantometer, followed the technical recommendations for the anthropometric measurement [11].

\subsection{Allocation and Definition of Variables}

In this study the socioeconomic and demographic variables of children and mothers was allocated in three hierarchy levels: basic, intermediate and immediate. The basic level is the economic factors of households, in the intermediate level are allocated the mothers and household sanitary conditions variables and in the immediate level, the children demographic characteristics and morbidity. In this study, the hierarchy model was adapted from the Unicef [15].

Outcome variables

This study adopted two outcome variables, weight for age (WAZ) z score and height for age (HAZ) $z$ score classified according to the reference values of the World Health Organization criteria [12]. These variables were categorized into three levels: state of eutrophic (reference $=0$ ) $[\mathrm{Z}$ score +4.99 to -1.0$]$; mild deficit: 1) [Z score $-1.01 \mathrm{SD}$ to $-2.0 \mathrm{SD}$ ]; moderate deficit (2) [Z score $-2.01 \mathrm{SD}$ to $<-3.01 \mathrm{SD}$ ]; 2) and severe deficit; 3) $\mathrm{Z}$ score $<-3.00 \mathrm{SD}$ and more.

Independent variables

Basic level: Possession of goods index (medium and tertil); Possession of domestic animals (tertil); type of water at home (potable water $=0$; non potable water = 1); the household own land (Yes = 0 , No = 1); Intermediate Level (age 
of mother 16 to $22=1 ; 23$ to $34=0 ; \geq 35=2$ ); Maternal education level (Secondary $=0$; Primary $=1$; unlettered $=2)$; household had a latrine (Yes $=0$, No $=$ 1 ); type of latrine (Improved latrine $=0$; unimproved latrine $=1$; no latrine $=2$ ); sharing a latrine with other households (Yes $=1$, No $=0$ ); Immediate level: children's sex $(\mathrm{M}=0, \mathrm{~F}=1)$; age in months $(0-6=0 ; 6.1-11.9=1 ; 12-23.9=$ 2, $24-59=3$ ); birth weight ( $>=2500 \mathrm{~g}=0$; $<2500 \mathrm{~g}=1)$; Morbidity and treatment cough Yes $=1$, No $=0$; child had diarrhea 15 days before the interview Yes $=1$, No = 0; child was deworming against helminths (Yes =0; No =1); Diet Exclusive breastfeed 0 to 6 months $=0$; complementary feed $=1$; mixed breastfeed artificial and maternal milk $=2$; and the family food $=3$ [13]. The evaluation of the child's food consumption was based on qualitative survey of food intake 24 hours prior to the interview.

\section{Statistical Analysis}

Data was analyzed using STATA software version 12:0. The polynomial regression an extension of logistic regression was used the outcome variables were categorized in more than two levels [14]. The hierarchical approach was adopted to identify the determinants of the underweight and stunting. Two models were adjusted, one for each anthropometric indicator. The predictor variables were allocated according to the hierarchy block in basic, intermediate and immediate level, adapted from the UNICEF [15]. The OR (odds ration) was used to examine the association between the socioeconomic factors and malnutrition in children.

Initially there was the univariate polynomial regression analysis taking into account all predictor variables allocated to each hierarchy block and variables with p values lower than $20 \%$ were included in the multivariate model. All associations with $\mathrm{p}$ value less than 0.05 in each hierarchy level of multivariate analysis were included in the final model. The value of $\mathrm{p}(0.05)$ and the confidence interval (CI) of $95 \%$ were adopted to accept the investigated associations in the final model.

\section{Results}

\subsection{Basic Level}

In this study, the anthropometric and socioeconomic characteristics of children are shown in Table 1 . The prevalence of underweight $(z$-score $<-2)$ was $13.9 \%$ and $(z$-score $<-3)$ was $5.7 \%$. The overall prevalence of underweight was $19.6 \%$. The prevalence of stunting ( $z$-score $<-2)$ was $24.2 \%$ and $(z$-score $<-3) 15.6 \%$. The overall prevalence of stunting was $39.8 \%$ (Table 1 ).

Half of households, $53.3 \%$ (Table 1 ) that had ( 0 or 1 ) durable goods were associated with underweight and stunting. The risk of malnutrition was significantly higher among children that had 1 or had not any durable goods in the household. Children who had 1 durable goods in a household were 1.46 times greater to be underweight $\mathrm{OR}=1.4695 \% \mathrm{CI}(1.01-2.11)$. In the households that had 1 durable goods, the prevalence of stunting in moderate and severe forms 
Table 1. Anthropometric and socio economic characteristics of children and their families in the districts of Angonia, Tsangano, Magoe and Changara in the Province of Tete in Mozambique, in 2012.

\begin{tabular}{|c|c|c|}
\hline Anthropometric state & $\mathrm{N}$ & $\%$ \\
\hline \multicolumn{3}{|l|}{ Weight for age (WAZ) (583) } \\
\hline Eutrofic & 290 & 49.7 \\
\hline Mild & 179 & 30.7 \\
\hline Moderate & 81 & 13.9 \\
\hline Severe & 33 & 5.7 \\
\hline \multicolumn{3}{|l|}{ Height for age (HAZ) (583) } \\
\hline Eutrofic & 145 & 24.9 \\
\hline Mild & 206 & 35.3 \\
\hline Moderate & 141 & 24.2 \\
\hline Severe & 91 & 15.6 \\
\hline \multicolumn{3}{|l|}{ Basic level } \\
\hline \multicolumn{3}{|c|}{ Durable goods in the household index (medium) (583) } \\
\hline 0 to 1 & 311 & 53.3 \\
\hline 2 to 8 & 272 & 46.7 \\
\hline Household own land (583) & 513 & 88 \\
\hline Household without own land & 70 & 12 \\
\hline \multicolumn{3}{|l|}{ Possess of domestic animals (tertil) } \\
\hline 0 to 1 animal & 162 & 27.8 \\
\hline 2 animals & 185 & 31.7 \\
\hline$\geq 3$ animals & 236 & 40.5 \\
\hline \multicolumn{3}{|l|}{ Water at home (583) } \\
\hline Safe water (Potable water) & 288 & 41.8 \\
\hline Non drinkable water & 355 & 60.9 \\
\hline Intermediate level & $\mathrm{N}$ & $\%$ \\
\hline \multicolumn{3}{|l|}{ Mother's age (years) (583) } \\
\hline 16 to 22 & 166 & 28.5 \\
\hline 23 to 34 & 319 & 54.7 \\
\hline$\geq 35$ & 98 & 16.8 \\
\hline \multicolumn{3}{|l|}{ The household has a latrine (583) } \\
\hline Yes & 342 & 59.4 \\
\hline No & 234 & 40.1 \\
\hline \multicolumn{3}{|c|}{ Sharing a latrine with other families (583) } \\
\hline Yes & 112 & 19.2 \\
\hline No & 471 & 80.8 \\
\hline \multicolumn{3}{|l|}{ Mother's education level (583) } \\
\hline Secondary & 68 & 10.8 \\
\hline
\end{tabular}




\section{Continued}

\begin{tabular}{|c|c|c|}
\hline Primary & 331 & 56.8 \\
\hline Unlettered & 189 & 32.4 \\
\hline Immediate level & $\mathbf{N}$ & $\%$ \\
\hline \multicolumn{3}{|l|}{ Child's age (months) (583) } \\
\hline $0-24$ & 398 & 68.3 \\
\hline $24.1-59$ & 185 & 31.7 \\
\hline \multicolumn{3}{|l|}{ Child's Sex (583) } \\
\hline Male & 287 & 49.2 \\
\hline Female & 296 & 50.8 \\
\hline \multicolumn{3}{|l|}{ Weight at birth (583) } \\
\hline$\geq 2500 \mathrm{~g}$ & 508 & 87.1 \\
\hline$<2500 \mathrm{~g}$ & 75 & 12.9 \\
\hline \multicolumn{3}{|l|}{ Child had cough* $(583)$} \\
\hline Yes & 225 & 38.6 \\
\hline No & 358 & 61.4 \\
\hline \multicolumn{3}{|l|}{ Child was deworming against helminthes* ${ }^{\star}(583)$} \\
\hline Yes & 190 & 32.6 \\
\hline No & 393 & 67.4 \\
\hline \multicolumn{3}{|l|}{ Child had diarrhea 15 days before the interview (583) } \\
\hline Yes & 176 & 30.2 \\
\hline No & 407 & 69.8 \\
\hline \multicolumn{3}{|l|}{ Children feeding (583) } \\
\hline Exclusive breastfeed & 34 & 5.8 \\
\hline Complementary breastfeed & 229 & 39.3 \\
\hline Mixed breastfeed (maternal and artificial milk) & 89 & 15.2 \\
\hline Family food & 231 & 39.7 \\
\hline
\end{tabular}

was $\mathrm{OR}=5.00(95 \%$ CI 2.16 - 6.99). Children that had 1 durable goods in the households were increased 5 times the risk to be stunting when compare with children with 3 to 8 durables goods (reference) (Table 2).

The households with ( 2 goods) ( $2^{\text {nd }}$ tertile) the stunting was OR $=3.12(95 \%$ CI 1.40 - 7.00) in moderate and severe when compared with the households which had 3 to 8 goods (reference) (Table 2). Children lived in the household with 2 durables goods were 3 times greater to be moderate and severe stunting.

The results of this study, showed that children who lived in the households without own land to agriculture practices were associated with mild underweight $\mathrm{OR}=1.98$ (CI95\% 1.02 - 3.82) (Table 2). The households with high economic and social vulnerability have children at risk to have malnutrition. Children of household had not the land to agriculture practices, were $98 \%$ risk to have underweight. 
Table 2. Adjusted OR for associations between exposure variables and anthropometric status, according weight to age and height for age, Tete Mozambique, in 2012.

\begin{tabular}{|c|c|c|c|c|c|c|c|c|c|c|c|c|}
\hline \multirow{3}{*}{ Variables } & \multicolumn{6}{|c|}{ Weight for Age (WAZ) } & \multicolumn{6}{|c|}{ Height for Age (HAZ) } \\
\hline & \multicolumn{3}{|c|}{ Mild deficit } & \multicolumn{3}{|c|}{$\begin{array}{l}\text { Moderate and } \\
\text { severe deficit }\end{array}$} & \multicolumn{3}{|c|}{ Mild déficit } & \multicolumn{3}{|c|}{$\begin{array}{l}\text { Moderate and } \\
\text { severe deficit }\end{array}$} \\
\hline & OR & $\mathrm{p}$-value & CI 95\% & OR & p-value & CI 95\% & OR & $\mathrm{p}$ value & CI 95\% & OR & $\mathrm{p}$ value & CI $95 \%$ \\
\hline
\end{tabular}

\section{Basic level}

Durable goods in the household index (medium)

2 to 8 goods (above medium)

$\begin{array}{lllllll}0 \text { to } 1 \text { goods (below medium) } & 1.46 & 0.037 & 1.02-2.11 & 1.30 & 0.219 & 0.85-1.99\end{array}$

Durable goods in the household index (Tertile)

$1^{\text {st }}$ Tertile ( 3 to 8 goods)

$2^{\text {nd }}$ Tertile ( 2 goods)

$3^{\text {rd }}$ Tertile ( 0 or 1 good)

1

$\begin{array}{llllll}2.71 & 0.013 & 1.23-5.96 & 3.12 & 0.006 & 1.40-7.00\end{array}$

$\begin{array}{llllll}1.81 & 0.180 & 0.76-4.31 & 5.00 & <0.001 & 2.16-6.99\end{array}$

The household owns land

$\begin{array}{lcccccc}\text { Yes } & 1 & & & & & \\ \text { No } & 1.98 & 0.04 & 1.02-3.83 & 0.55 & 0.29 & 0.18-1.69\end{array}$

Intermediate level

Latrine type

Improved latrine

1

Non improve latrine

$\begin{array}{llll}1.17 & 0.52 & 0.71-1.91 & 1.42\end{array}$

0.25

$0.77-2.59 \quad 1.89$

0.12

$0.83-4.25 \quad 2.17$

$0.044 \quad 1.02-4.61$

No latrine

1.15

$0.58 \quad 0.69-1.90 \quad 2.01$

$\begin{array}{lll}0.02 & 1.09-3.70 & 2.21\end{array}$

$\begin{array}{lll}0.06 & 0.96-5.07 \quad 1.78\end{array}$

$0.149 \quad 0.01-3.88$

The household shared

latrine with families

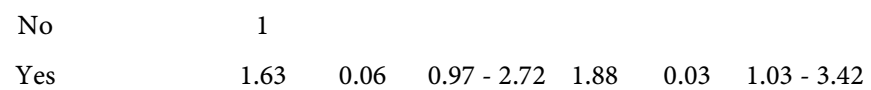

Maternal education level

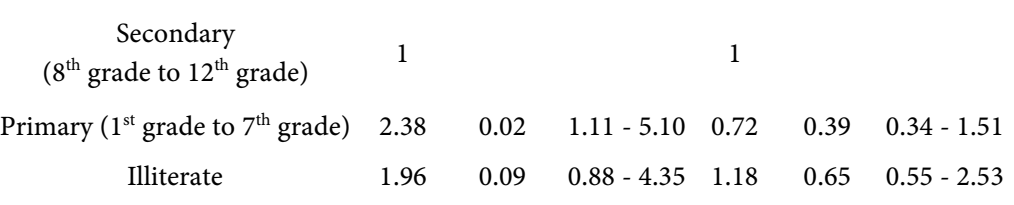

Immediate level

The child was deworming*

\begin{tabular}{lcccccc} 
No & 1 & & \multicolumn{1}{c}{1} \\
Yes & 0.94 & 0.79 & $0.61-1.45$ & 1.91 & 0.02 & $1.07-3.40$
\end{tabular}

The child had cough*

\begin{tabular}{lcccccc} 
No & 1 & \multicolumn{5}{c}{1} \\
Yes & 1.29 & 0.22 & $0.85-1.95$ & 2.42 & $<0.01$ & $1.49-3.93$
\end{tabular}

The child took breastfeed ${ }^{* *}$

\begin{tabular}{lccccccc} 
Yes & 1 & & & 1 & & \\
No & 1.16 & 0.06 & $0.61-2.20$ & 1.91 & 0.04 & $1.04-3.52$ \\
\hline
\end{tabular}

${ }^{*} 15$ days before the interview; ${ }^{* *}$ the interview date. 


\subsection{Intermediate Level}

In the intermediate level, $19.2 \%$ of the households shared the same latrine, in the communities (Table 1). This study shown that children that lived in the households without latrine increased in 2.01 times greater OR $=2.0195 \%$ (CI 1.09 3.70) in moderate and severe underweight and unimproved latrine $\mathrm{OR}=2.17$ 95\% (CI 1.02 - 4.61) increased in 2.17 times greater the moderate and severe stunting when compared with those that had the improved latrine (Table 2).

In this study, mothers with primary educational was associated with mild underweight in children OR $=2.3895 \%$ (CI: 1.11 - 5.10). Children of mothers with primary school had 2.38 times greater to be mild underweight when compared with children of mothers with secondary or high school (reference) Table 2.

\subsection{Immediate Level}

This study showed that the children up to 2 years who were in breastfeeding adequately had a protective effect of breastfeeding, especially for the children living in the better conditions, when compared to those that had not in breastfeeding OR 1.91 95\% (CI 1.04 - 3.52). Children did not breastfeeding were 91\% times greater to be moderate and severe stunting when compared with those breastfeed.

\section{Discussion}

\subsection{Basic Level}

In this study, the prevalence of overall malnutrition (underweight was $50.3 \%$ and stunting $75.1 \%$ ), the prevalence of moderate and severe underweight was 19.6 this prevalence was lowest when compared with $36 \%$ of moderate and severe prevalence of underweight reported by UNICEF in Madagascar [16]. This prevalence of underweight were similar that reported in Madagascar by Rakotomanana et al., found the prevalence of stunting in children under 5 years was extremely high (48.5\%) [17]. This results show that in developing countries, the prevalence of malnutrition in children under five years is extremely high. In this study, the prevalence of severe stunting is $15.6 \%$ although, in different finding was reported by Nampossa et al. the prevalence of severe stunting among sick children was $11 \%$ in Manhiça district, Mozambique [18]. Curiously the results reported by Nampossa et al., were lowest than the one observed in this study (15.6\%).

In Mozambique, the prevalence of severe stunting in children under five years remains high 19.7\% [19]. In India, Buthia et al. reported the prevalence of stunting was $48 \%$ in children under the age of five [20] These results shown that the malnutrition in children under five years is a challenge in developing countries such as Mozambique.

In this study, half of households (53.3\%) had ( 0 or 1$)$ durable goods, this result is similar to reported by Babatundi et al., in Nigeria that revealed children from richer households were less malnourished than those from poorer house- 
holds [21]. This results shows that children from richest families were more protected from undernutrition when compared with those children from the household without durable goods.

The results of this study, revealed that children who lived in the households without own land were associated with mild underweight OR $=1.98$ CI95\% (1.02 - 3.82). Similar results were reported in other countries in few decades ago, in Brazil when the prevalence of malnutrition was high, especially in the north and northeast, children that households had not the own land were more malnourished [22] [23]. These findings were observed in children that had failure of liner growth in some African countries, like Kenya [24] and Ghana [25] in other countries such as India [26] and Brazil [27], are some reports of anthropometric deficits in children.

In Mozambique, the diets are monotonous and contains few micronutrients, the food insecurity is frequently in rural areas. This conditions affects many young children. If the government in coordination with Ministry of Health and Ministry of Agriculture and Food Security provides food fortification with multi-micronutrients, food security in the households and balanced diet, will improve the nutritional status of the children, especially in the rural areas.

\subsection{Intermediate Level}

In this study, $19.2 \%$ of the households shared the latrine with others families in the communities, the same finding was observed in Siri Lanka [28]. This study showed that children that lived in the households without latrine increased the chance to be moderate and severe underweight and those who lived in household with unimproved latrine increased chance to be moderate and severe stunting.

In Tete province share the latrine is less frequent. This study showed that shared the latrine with other families was associated with moderate and severe underweight in children OR $=1.88$ (95\% CI 1.03 - 3.42). Sharing the latrine with other households is not good for health due to hygienic condition. So, a better sanitary conditions prevent diseases such as diarrhoea, cholera and malnutrition.

These findings corroborate with reports of other studies carried out in the rural areas in Ethiopia [29]. In this sense, the Department for International Development in UK [30] identified some intervention and actions to be taken in order to promote hygiene and sanitation to improve the health in children.

In this study, children of mothers with primary school had 2.38 times greater to be mild underweight. The maternal education is strongly associated with children nutritional status the; results of other study that examined the association between maternal education and nutrition status in children showed the inverse correlation between the maternal education and children malnutrition.

The results of study carried out in developing countries in Sub-Saharan Africa (Malawi, Tanzania and Zimbabwe) examined the influence of the maternal 
educational and nutritional status of children, showed the inverse correlation. The maternal education level is necessary to make a significant reduction in children malnutrition is at least 9 years of schooling in Malawi, 5 years of schooling in Tanzania and at least 8 years of schooling in Zimbabwe [31].

In Mozambique the influence of maternal education was reported, mothers with secondary or high school used frequently the health services, improved the health and hygiene practices when compared with those unschooled mothers [32]. Similar results were reported in Ghana [33] and Pakistan [34]. In countries that the low maternal education is frequent, the access of women to health service is deficient.

\subsection{Immediate Level}

This study showed that the children that were deworming in the 2 weeks before the interview, were associated with underweight and stunting. The association between intestinal parasites and anthropometric deficit in children was reported in the developing countries, such as Nigeria [35], Uganda [36] and Malaysia [37].

This study reported that the cough was associated with moderate and severe stunting OR $=2.42$ (95\% CI 1.49 - 3.93). The Government of Mozambique is carrying out the multisectoral plan for chronic malnutrition reduction to promote the health and reduce the undernutrition in children.

\section{Conclusion}

The study shows that the malnourished children under the age of 5 are a serious public health problem in the province of Tete, Mozambique. It is associated with basic, intermediate and immediate factors. It is necessary to continue improve the health, nutrition and food programs in the rural areas.

\section{Conflicts of Interest}

The authors declare no conflicts of interest regarding the publication of this paper.

\section{References}

[1] Amsalu, S. and Tigabu, Z. (2008) Risk Factors for Severe Acute Malnutrition in Children under the Age of Five: A Case Control Study. Ethiopian Journal of Health Development, 22, 1-5. https://doi.org/10.4314/ejhd.v22i1.10058

[2] World Bank (2014) Child Malnutrition/Regional-Trends. http://data.worldbank.org/child-malnutrition/regional-trends

[3] Ministério da Saúde (MISAU) (2013) Instituto Nacional de Estatística (INE) e ICF International (ICFI). Moçambique Inquérito Demográfico e de Saúde 2011. Calverton, Maryland, USA, MISAU, INE e ICFI.

[4] Kandala, N.B., Madungu, P.T., Emina, B.O.J., Nzita, K.P. and Cappuccio, F.P. (2011) Malnutrition among Children under the Age of Five in the Demographic Republic of Congo (DRC). Does Geographic Location Matter? BMC Public Health, 
11, 261. https://doi.org/10.1186/1471-2458-11-261

[5] Meshram, I.I., Arlappa, N., Balakrishna, N., Rao, K.M. and Laxamaiah, A. (2012) Trends of Prevalence of Undernutrition Nutrient \& Food Intake and Predictors of Undernutrition among under Five Year Tribal Children in India. Asia Pacific Journal of Clinical Nutrition, 21, 568-576.

[6] MICS (Multiple Indicators Cluster Survey) (2008) Mozambique Final Report. Maputo, Mozambique, $216 \mathrm{p}$.

[7] WORLD FOOD PROGRAM (2010) Comprehensive Food Security and Vulnerability Analysis, Data Collected between August-September Mozambique.

[8] Cruz, L.M.G., Azpeitia, G.G., Súarez, D.R., Rodríguez, A.S., Ferrer, J.F.L. and Majem, L.S. (2017) Factors Associated with Stunting among Children Aged 0 to 59 Months from the Central Region of Mozambique. Nutrients, 9, E491.

https://doi.org/10.3390/nu9050491

[9] UNICEF (2010) Child Poverty and Disparities in Mozambique. Maputo, $134 \mathrm{p}$.

[10] WHO (ORGANIZAÇÃO MUNDIAL DA SAÚDE) (1995) El estado físico: Uso e interpretacion da antropometría. OMS serie de informes técnicos. Ginebra.

[11] Lohman, T.G., Roche, A.F. and Martorell, R. (1998) Anthropometric Standardization Reference Manual. Human Kinetics Books, Champaign, Illinois.

[12] WHO/UNICEF (2009) Child Growth Standards and the Identification of Severe Acute Malnutrition in Infants and Children. A Joint Statement by the World Health Organization and the United Nations Children's Fund.

[13] WHO/UNICEF (2008) Indicators for Assessing Infant and Young Child Feeding Practices. Global Consensus Meeting on Indicators of Infant and Young Child Feeding, Washington DC, 6-8 November 2007.

[14] Wickens, T.D. (1998) Categorical Data Analysis. Annual Review of Psychology, 49, 537-557. https://doi.org/10.1146/annurev.psych.49.1.537

[15] UNICEF (1990) Police Review Strategy for Improved Nutrition of Children and Women in Developing Countries. Unicef, New York.

[16] UNICEF (2009) Tracking Progress on Child and Maternal Nutrition: A Survive and Development Priority. New York.

[17] Rakotomanana, H., Gates, G.E., Hildebrand, D. and Stoecker, B.J. (2017) Determinants of Stunting in Children under 5 Years in Madagascar. Maternal \& Child Nutrition, 13, 12409.

[18] Nhampossa, T., Sigaúque, B., Machevo, S., Macete, E., Alonso, P., Bassat, Q., Menéndez, C. and Fumadó, V. (2013) Severe Malnutrition among Children under the Age of 5 Years Admitted to a Rural District Hospital in Southern Mozambique. Public Health Nutrition, 16, 1565-1574. https://doi.org/10.1017/S1368980013001080

[19] Mozambique (2011) Multisectoral Action Plan for Reduction of Chronic Undernutrition in Mozambique, 2011-2015 (2020); Maputo, 117 p.

[20] Bhutia, D.T. (2014) Protein Energy Malnutrition in India: The Plight of Our Under Five Children. Journal of Family Medicine and Primary Care, 3, 63-67.

[21] Babatunde, R.O., Olagunju, F.I., Sola-Ojo, F.S.B. and Eunice, F. (2011) Prevalence and Determinants of Malnutrition among Under-Five Children of Farming Households in Kwara State in Nigeria. Journal of Agriculture Sciences, 3, 173-179.

[22] Lira, P.I.C., Cartagena, H.A., Mello, S.A., Torres, M.A. and Malaquias, C. (1985) Estado nutricional de crianças menores de 6 anos, segundo posse de terra em área rural no Estado de Pernambuco, Nordeste do Brasil. [Nutritional Status of Children 
under 6 According to the Land Tenure in Rural Areas of the State of Pernambuco]. Northeast of Brazil, 35, 247-257.

[23] Assis, A.M.O., Freitas, M.C.S., Prado, M.S.P. and Oliveira, N.M. (1987) Expropriação e fome. Empresa Gráfica da Bahia. 163 p.

[24] Kabobu-Mariara, J., Ndenge, G.K. and Mwabu, D.K. (2008) Determinants of Children Nutritional Status in Kenya: Evidence from Demographic and Health Surveys. Journal of African Economies, 3, 363-387.

[25] Anderson, A.K., Bignell, W., Winful, S., Soyiri, I. and Asiedu, S.M. (2010) Risk Factors among Children 5 Years and Younger in the Akuapim North District in the Eastern Region of Ghana. Current Research Journal of Biology Sciences, 2, 183-188.

[26] Subramanyam, M.A., kawachi, I., Berkman, L.F. and Subramanian, S.V. (2010) Socioeconomics Inequalities in Childhood Undernutrition in India: Analyzing Trends between 1992 and 2005. PLoS One, 6, 11392.

[27] Oliveira, V.A., Assis, A.M.O., Pinheiro, S.M.C. and Barreto, M.L. (2006) Determinants dos déficits ponderal e do crescimento linear em menores de dois anos. [Determinants of Weight and Linear Growth Deficits in Children under 2 Years of Age]. Revista de Saúde Pública, 874-882.

[28] Galgamuwa, L.S., Iddawela, D., Dharmaratne, S.D. and Galgamuwa, G.L.S. (20017) Nutritional Status and Correlated Socio-Economic Factors among Preschool and School Children in Plantation Communities, Sri Lanka. BMC Public Health, 17, 37.

[29] Medhin, G., Hanlon, C., Dewey, M., Alem, A., Tesfaye, F. and Worku, B. (2010) Prevalence and Predictors of Undernutrition among Infants Aged Six and Twelve Months in Butajira, Ethiopia: The P-MaMiE Birth Cohort. BMC Public Health, 10, 27. https://doi.org/10.1186/1471-2458-10-27

[30] Department for International Development (2011) The UK's Position Paper on Undernutrition.

[31] Makoka, D. and Masibo, P.K. (2015) Is There a Threshold level of Maternal Education Sufficient to Reduce Child Undernutrition? Evidence from Malawi, Tanzania and Zimbabwe. BMC Pediatrics, 15, 96.

[32] Burchi, F. (2010) Child Nutrition in Mozambique in 2003: The Role of Mother's Schooling and Nutrition Knowledge. Economic and Human Biology, 8, 331-345. https://doi.org/10.1016/j.ehb.2010.05.010

[33] Greenaway, E.S., Leon, J. and Baker, D.P. (2012) Understanding the Association between Maternal Education and Use of Health Services in Ghana: Exploring the Role of Health Knowledge. Journal of Biosocial Science, 44, 733-747.

[34] White, E. and Nisar, N. (2003) Factors Affecting Utilization of Antenatal Care among Reproductive Age Group Women (15 - 49 Years) in an Urban Squatter Settlement of Karachi. Journal of Pakistan Medical Association (Paquistan), 2, 47-53.

[35] Opara, K.N., Udoidung, N.I., Opara, D.O.C., Okon, O.C. and Edosowan, E.U. (2012) The Impact of Intestinal Parasitic Infections on the Nutritional Status of Rural and Urban School Aged Children in Nigeria. International Journal of $\mathrm{MCH}$ and AIDS, 1, 73-82.

[36] Francis, L., Kirunda, B.E. and Orach, C.G. (2012) Intestinal Helminth Infections and Nutritional Status Attending Primary Schools in Wasiko District Central of Uganda. International Journal of Environment Research and Public Health, 9, 2910-2921.

[37] Wong, H.J., Moy, F.M. and Nair, M. (2014) Risk Factors of Malnutrition among Preschool Children in Terengganu Malaysia: A Case Control Study. BMC Public Health, 14, 785 . 